OPEN ACCESS

Edited by:

Daniel Fischer,

Wageningen University and Research,

Netherlands

Reviewed by:

Mandy Singer-Brodowski, Freie Universität Berlin, Germany

Marlyne Sahakian,

Université de Genève, Switzerland

Juergen Budde,

University of Flensburg, Germany

*Correspondence:

Denis Francesconi

denis.francesconi@univie.ac.at

Evi Agostini

evi.agostini@univie.ac.at

Specialty section:

This article was submitted to

Special Educational Needs,

a section of the journal

Frontiers in Education

Received: 30 November 2020

Accepted: 04 May 2021

Published: 28 June 2021

Citation:

Francesconi $D$, Symeonidis $V$ and Agostini E (2021) FridaysForFuture as

an Enactive Network: Collective

Agency for the Transition Towards

Sustainable Development.

Front. Educ. 6:636067.

doi: 10.3389/feduc.2021.636067

\section{FridaysForFuture as an Enactive Network: Collective Agency for the Transition Towards Sustainable Development}

\author{
Denis Francesconi ${ }^{1,2 *}$, Vasileios Symeonidis ${ }^{3}$ and Evi Agostini ${ }^{4 *}$ \\ ${ }^{1}$ Danish School of Education, Aarhus University, Aarhus, Denmark, ${ }^{2}$ Department of Teacher Education, University of Vienna, \\ Vienna, Austria, ${ }^{3}$ Institute of Education Research and Teacher Education, University of Graz, Graz, Austria, ${ }^{4}$ Department of \\ Teacher Education and Department of Education, University of Vienna, Vienna, Austria
}

In this article, we provide a theoretical conceptual analysis of FridaysForFuture (FFF) and of its effort in promoting the governance of socioeconomic transition toward sustainable development. FFF is a social movement that has received outstanding public recognition and visibility across the world in the last 2 years and is of great interest to educational research because it is largely composed of youngsters and appears to play a paideutic role in societal innovation. There is a growing but still limited body of investigation of FFF's structures, genealogy, and behavior. The same goes for its theoretical and ethical background and principles. Its efforts to promote social change by going beyond individual agency toward collective agency deserve greater attention from educational scientists. We argue that FFF is a complex, self-organizing, informal network, which we define as an enactive network for its ability to retrieve scientific knowledge and transform it into lived meaningful knowledge, and for its capacity to mobilize masses and influence public discourse under a specific ethical umbrella. We provide six macro categories to describe and explain FFF: 1) nested emergent network, 2) collective social agency and leadership, 3) political impact, 4) science-based learning and activism, 5) paideutic function, and 6) ethical (normative) stance. We stress the FFF capacity to recruit high-level scientific knowledge without direct support from schools, and embody strong ethical stances with specific references to the ethics of responsibility and care for the interaction between humanity and the natural world. Finally, we suggest that FFF can be interpreted as an enactive network with the ability to affect collective identity and empower collective agency by encouraging communities into a more scientific, evidence-based, and ethical public discourse.

Keywords: FridaysForFuture, enactive network, collective agency, education for sustainable development, climate change, enactive embodied cognition, systems theory, socio-ecological systems

\section{INTRODUCTION}

Recent socioeconomic and ecological crises, such as COVID-19 and climate change, have presented serious challenges to human systemic homeostasis, safety, and continuity, and require prompt and adequate responses from human communities. The response of human systems to such novel and profound crises, however, cannot consist of the mechanical implementation of a preestablished set of behaviors or values, as normally happens in the context of standard emergency procedures with the 
automatic implementation of detailed preplanned actions (e.g., emergency evacuation of a ship). The current crisis in which the whole of humanity find itself is new, profound, and dramatic, and standard responses do not seem adequate in the face of such situations (Steffen et al., 2015; Walker et al., 2020). Human communities' capacity to respond should rather be conceived of as a dynamic, iterative process of coevolution between the response itself and the evaluation of the effects of previous responses, as is the case with continuous behavior monitoring (Clark, 2013). Moreover, the coevolution of action and response evaluation is usually supervised by normative ethical stances intended to provide intentional teleology and values frameworks that make evaluation possible. No collective and systemic human actions are neutral in their assumptions-or in their consequences-as they tend to derive from a set of ethical principles that guide practical decision-making, at least formally. It is well established that profound crises such as the current one require new ethical frameworks that are capable of prompting new responses and strategies (Folke et al., 2005; Steffen et al., 2015; Walker et al., 2020).

In this study, we provide a theoretical conceptual analysis of FridaysForFuture (FFF) and its intended aim of effecting socioeconomic and ecological changes through the promotion of sustainable development in its various forms. FFF is a macrosocial movement that has received outstanding public recognition worldwide and gained visibility over the last 2 years. It is of great interest to educational research since it is largely composed of youngsters and seems to play a paideutic role in relation to societal innovation, being able to autonomously collect and share complex forms of scientific knowledge, transforming them and then enacting them in society in order to trigger collective awareness and agency. In contrast with formal schooling, FFF is a bottom-up movement, an emergent self-organizing network, providing pedagogical activities to peers and adults to support the sustainability discourse and promote social engagement at all levels of society (Kühne, 2019; Stratton, 2021). We argue that FFF is a complex, nested, and informal network, which we define as an enactive network due to its capacity to retrieve scientific knowledge and transform it into lived knowledge enacted in the real world. FFF aims to distribute such knowledge, mobilize large numbers of people, and influence public discourse under an explicit though nonhomogeneous ethical umbrella.

Social movements are powerful arenas for learning how to initiate societal change, gain transformative agency, and develop critical thinking (Kajamaa and Kumpulainen, 2019). The motivational and interactional intensity of social movements is often seen as a desirable model for human learning and education in general (Sannino et al., 2016). There is vast literature in the field of learning and social movements. However, little research has been conducted from the point of view of enactive theory and enactive learning within social movements, especially within FFF. With our study, we want to contribute to establish enactive theory as a paradigm for the study of learning within social movements. Our hypothesis is that FFF represents an innovative model for connecting learning and activism, education and politics, embodied and virtual life, and individual and collective perspectives, and for promoting students' agency as well as student-scientist collaboration on sustainable social innovation.

So far, there has been scarcely any investigation of FFF's structures, genealogy, and behavior (Cattell, 2021). The same goes for its theoretical, pedagogical, political, and ethical background and principles (Biswas and Mattheis, 2021). As highlighted by Shove (2010), issues of climate change are often (politically) framed in terms of individual behavior and personal responsibility. However, values and ideals do not often result in action, attitude, or behavioral change. Nonetheless, the efforts of FFF to promote social and ecological change through collective agency go beyond mere individual agency and deserve more attention from educational scientists. We use embodied and enactive cognition theory (EC) (Gallagher and Francesconi, 2012; Varela et al., 2016) and systems theory (Folke et al., 2005; Papachristos et al., 2013) as theoretical frameworks for analyzing the collective agency and pedagogical-ethical implications of FFF.

In line with the theme of this special section, we aim to describe the primacy of collective agency over individual agency in FFF in the face of the increasing urgency of sustainability-related transformation and to provide theoretical conceptual insights as the basis for further educational research. Instead of focusing exclusively on intraindividual behavior analysis, we propose the enactive and systemic approach to frame and explain how collective agency is becoming predominant in the development of solutions to the crisis. Such a comprehensive perspective not only increases the ecological credentials of psychological and educational research but also provides fruitful insight into guiding realworld transformation processes toward sustainability. Our study undertakes theoretical conceptual analysis (Kahn and Zeidler, 2017) of the FFF's structure and behavior in order to provide specific answers.

This article focuses on three points. First, it explains why systemic and enactive approaches can provide new insights into FFF's embodied knowledge and agency. Second, it develops six analytic descriptors of FFF in order to offer a richer description of FFF that should be of use to the scientific community in the context of further theoretical and empirical analyses of this and similar social phenomena. Third, drawing on our theoretical conceptual analysis, we provide insights into, and interpretations of, the role of FFF. The article concludes with suggestions for research to foster sustainable development.

\section{ENACTIVE NETWORK: EMBODYING KNOWLEDGE}

A range of environmental psychology and education research has explored sustainability-related learning and behavior at the level of the individual (Giusti et al., 2017; Albrecht, 2020). Various theories from social and behavioral psychology and the educational sciences have been applied to gain an understanding of the awareness, motivation, and normative aspects underlying the ecologically and socially responsible use of resources (Roczen et al., 2014). Non-reductionist approaches 
such as the embodied cognition theory and enactivism have also been brought to the exploration of these topics, but they continue to focus on the individual and on small-scale aspects of sustainability (Giusti et al., 2017; Albrecht, 2020). We apply embodied and enactive cognition theory (EC) (Thompson, 2007; Francesconi and Tarozzi, 2012; Gallagher and Zahavi, 2012; Varela et al., 2016) to FFF as a social movement that is keen to draw attention to sustainability issues.

EC is a relatively new research program within cognitive science that has spread into philosophy, psychology, neuroscience, and education ( $\mathrm{Di}$ Paolo et al., 2010; Francesconi and Tarozzi, 2012; Agostini and Francesconi, 2020; Ryan and Gallagher, 2020). It is strongly critical of both Cartesian dualism - the ontological separation of body and mind and subject and nature-and computationalism - the view of the mind as an information-processing computer (Froese and Di Paolo, 2011; Gallagher, 2014). Enactivism looks at the mind and cognition as the process that emerges from the nonlinear interaction of the brain-body-environment (Thompson, 2007; Francesconi and Tarozzi, 2012; Gallagher and Zahavi, 2012; Varela et al., 2016). The enactive approach emphasizes biological embodiment and social interaction as the sources of real-life goals and concerns. Mind is viewed as active sensemaking in the context of embodied interaction with the world. Enactive cognition means that knowledge is acted out in the real lived world (Lebenswelt) in a constant attribution of sense to the lived experience (Gallagher, 2014; Kiverstein and Rietveld, 2018). In this sense, the enactive approach does not consider the mind merely as a receptacle for information. The enactive mind, although undoubtedly involved in the cybernetic cycle of information input and output, goes far beyond that, suggesting that cognition represents the capacity of the subject as an agent to produce sense from being-in-the-world, in the ongoing subjective experience defined by a specific body, a specific environment, and in a specific moment (Thompson, 2007; Kiverstein and Rietveld, 2018; Ryan and Gallagher, 2020). Thus, knowledge is not represented as if in a mirror but instead is embodied and carried forward in interaction with the world. Enactive cognition helps to bridge the gap between mind and nature and between the individual and the collective, and can support the study of the interplay between collective agency and social structures (Froese and Di Paolo, 2011; Maiese and Hanna, 2019; Ransom and Gallagher, 2020). This theoretical position is now widely accepted by cognitive scientists, philosophers, and psychologists engaged in describing and studying the individual mind (Shapiro, 2014; Newen et al., 2018). Nevertheless, what can enactive cognition say about the collective mind, and collective movements and organizations? This theme has had less investigation and has been less extensively clarified.

Against this background, collective agency in the context of climate change as seen in FFF can be understood as a dynamic counterweight to formal education since it is based on the provision of opportunities for children to learn directly from peers and scientists. This social movement also invites us to rethink the formal boundaries of education systems/schools and challenges us to investigate further the pedagogical potential of bottom-up informal networks (see FridaysForFuture: An Enactive Network? section). Whereas the systems theory is relatively common in environmental and ecological studies (Folke et al., 2005), the choice of EC is original because, so far, embodied and the enactive theory has generally been applied to the study of intrapersonal, personal, or small group activities and not to larger scale intersubjective social movements, organizations, or institutions. This is partially understandable as EC was developed within the cognitive sciences during the 1990s, when the study of the mind was dominated by experimental psychology, neuroscience, and biology. Research at that time was focused on intrapersonal and personal descriptions rather than social, collective, and political ones. However, the lack of attention given by EC to macro-social activities is surprising when we consider that the original text on EC-entitled "The Embodied mind. Cognitive science and human experience" (Varela et al., 2016)-devoted an entire chapter to the theme of social mind as seen from the enactive perspective (see chapter 6). Only recently, some initial attempts have been made to extend the application of enactivism to macro-social phenomena. Relevant examples are Maise and Hanna's enactive approach to political science and politics (2019), and a few attempts to take an enactive approach to institutions and economics (Petracca and Gallagher, 2020; Ransom and Gallagher, 2020). Our study follows the same line of thinking, which we believe has potential for the social sciences and educational science; we adopt EC as a theoretical lens through which to consider FFF and explore its attempts to bridge the gaps between mind and nature, the individual and the collective, and the personal and the social, from a normative, political, and ethical perspective.

In doing so, the first points to consider in terms of convergence of individual enactivism and macro-social phenomena are that even macro-social phenomena-such as FridaysForFuture and others-have identity and intentionality, intrinsic beliefs, norms, and thoughts, and demonstrate future-oriented, predictive behavior framed in a way that is meaningful for the network (Petracca and Gallagher, 2020; Ransom and Gallagher, 2020). Such networks are of necessity embodied by specific individuals, embedded in a given physical and social environment, and enacted in the real world through consciousness and intentionality.

Now, the capacity to govern the transition at the systemic level, more than the transition itself, is said to be a critical issue for our times (Walker et al., 2020). There is a lack of systemic governmental capacity to direct collective agency in an inclusive, participative, and responsible manner (Lima, 2019). The capacity to control human systems during socio-ecological transitions has been related to the cognitive and learning capacities of systems themselves (Folke et al., 2005; Smith et al., 2005). Acquiring and distributing knowledge, advocating for a specific common ethical narrative and teleology, and calling for a global identity and awareness are all enactive features brought by FFF to the table of public discourse. In the following section, we discuss six theoretical conceptual features of FFF from the EC and systemic perspectives. 


\section{FRIDAYSFORFUTURE: AN ENACTIVE NETWORK?}

On August 20, 2018, the then 15-year-old student Greta Thunberg posted an image of herself outside Sweden's parliament holding a handmade cardboard sign reading "Skolstrejk för klimatet" (school strike for climate). She was demonstrating alone against the lack of action on climate change by the Swedish government. Soon afterward, the hashtags \#FridaysForFuture (FFF) and \#SchoolStrikeforClimate went viral and became a worldwide social movement involving thousands of young people and adults both online and in the streets, and attracting media and political attention. In 2019, several other networks emerged in support of FFF, such as ScientistsforFuture (S4F), EntrepreneursforFuture (E4F), SchoolsforFuture, TeachersforFuture, and ParentsforFuture. The initial activity of just one teenager-more recently supported by other communities and interests coming together, for example, the degrowth movement and the green economy-has snowballed hugely and inspired many others, growing from one individual to thousands of people all around the world in only two years. Today, there are over 200 regional, national, and international FFF Social Media channels (Instagram, Twitter, YouTube, and Facebook) with over 20 million followers (FridaysForFuture, 2020a). The school strikes in the last year before the COVID-19 emergency involved millions of people all around the world, making FFF one of the biggest social movements in human history (FridaysForFuture, 2020b). The 2019 Global Week for Future, for instance, was a series of 4,500 strikes across more than 150 countries, focused around Friday 20 September and Friday 27 September. Likely the largest climate strikes in world history, the 20 September strikes, attracted roughly 4 million protesters; many of them were schoolchildren (idem).

One study has shown that FFF is composed of very young people, mostly female (Wahlström et al., 2019), and another recently revealed that FFF is contributing to climate change awareness (Deisenrieder et al., 2020). FridaysForFuture has spread through both the embodied and the virtual dimensions. The embodied dimension consists of real actions such as school strikes, discourses, initiatives (e.g., Lausanne Declaration and Unite Behind Science initiative), and educational activities (FFF's training campus and courses, e.g., Smile Campus 2019) (FridaysForFuture, 2020a). The virtual dimension arose immediately after Greta Thunberg's first strikes, with the twitter hashtags starting to spread quickly within the online community. With the onset of the COVID-19 pandemic, the virtual dimension has become even more important. Consisting mostly of a community of digitally literate youngsters, FFF adapted immediately to the new situation, switching to virtual strikes, online training and learning activities, and digital activism (Hunger and Hutter, 2020).

Below, we present six categories that we have adopted as analytic descriptors of FFF and that could also be adopted in qualitative and quantitative empirical studies in further educational and psychological research into the nature, functions, and impact of FFF's collective agency or other emergent enactive movements. The six categories emerged from the theoretical conceptual analysis (Kahn and Zeidler, 2017) of FFF documents and websites.

\section{Nested Emergent Network}

The complex systems theory and enactive cognition suggest that FFF can be considered as a complex dynamic network composed of a range of other nested networks; it is like a meta-network with a fractal structure based on multilevel agency and distributed learning (Castellano et al., 2009; Clark, 2013; Rodi et al., 2015). Such a meta-network operates as an informal network and also aims to bring innovative potential to typical school structures, which are often centralized, hierarchical, and disembodied (Francesconi and Tarozzi, 2012). FFF has a nested and fractal structure both internally and externally (extended). Despite the existence of a central core represented by FridaysForFuture International, there is no strict hierarchical organization. Instead, it espouses bottom-up activism and personal collaborative engagement (FridaysForFuture, 2020a; Whang, 2020). Indeed, there are a number of smaller groups operating as sibling nodes of the macro FFF network. Such nodes are themselves nested and fractal. Consideration of one of them, for instance, FFF Italy, reveals a number of sub-nodes operating under distributed logic, such as FFF Rome, FFF Milan, and FFF Naples. This kind of fractal structure extends downward to individual schools or even classrooms and students.

This aspect-the highly interconnected and entangled internal structure of FFF-is of relevance for at least two reasons: first, it demonstrates a high capacity for self-organization based mostly on nonhierarchical and distributed leadership and agency. This is a rare attribute in vast and complex international networks and is something many formal organizations and companies constantly seek to achieve but hardly ever accomplish. Second, all layers of the systems appear to be interconnected both in reality and virtually. This increases knowledge transmission and improves the coordination of action but also boosts participation and engagement (Deisenrieder et al., 2020). In addition to its internal structure, FFF has developed an external network that extends into other fields such as science and economy but also draws in schools and parents. Indeed, FFF has created collaborations with a new range of networks-which are similar to FFF and emerged as one of the concrete side effects of FFF-such as Scientists4Future, Entrepreneurs4Future, Teachers4Future, and Parents4Future. Such expansion is vital for FFF. For instance, it is from the connection with Scientists4Future that FFF gains most of the technical and scientific knowledge used in its discourses and initiatives, and that it then disseminates via its own social media accounts. Moreover, it is in partnership with entrepreneurs, teachers, parents, and politicians-and again with scientists-that FFF has developed most of its specific sustainability solutions (FridaysForFuture, 2020a).

In this sense, the extended organization of FFF amplifies its capacity to put collective ideas into action, and to bring collective sustainability ideals and ethical values into the real world ( $\mathrm{Di}$ Paolo et al., 2010; Zabern and Tulloch, 2020). FFF is both an embodied and a digital movement, and it brings enactivism as 
knowledge-in-action to both the real and the virtual world, showing that the two dimensions are not only compatible but can actually reinforce each other in a nexus of interactions that would certainly merit further investigation. The movement began with an embodied - and solitary-action by Greta Thunberg, but this action soon reverberated in the virtual world, and from there, in a self-reinforcing loop, it grew rapidly to become one of the most relevant social movements of the last decade (FridaysForFuture, 2020b). That first embodied action had an impact on the online world, and the online world then triggered more embodied actions in the real world, and so on for 2 years, creating the highly interconnected structure of FFF today (Brünker et al., 2019).

\section{Collective Social Agency and Leadership}

Combining collective agency with strong iconic leadership is a complicated undertaking, but FFF seems to have succeeded. Collective agency means that a system is able to act as a unity, to behave in a coordinated manner in line with a common narrative, and to pursue common goals (Brünker et al., 2019). The relationship between individual intentionality and its behavior is often not linear and unclear; group's agency is even more problematic due to the high number of individuals-and therefore the many individual purposes-that it is composed of. The bigger the system, the harder it is for it to feel and behave like a unity. Size is a direct indicator of group cohesion or division (Castellano et al., 2009). Like many other social movements in history, but probably more so than many, FFF demonstrates significant capacity to combine the empowerment of bottom-up collective agency and identity with a strong and highly recognizable leadership (Stratton, 2021). FFF appears to behave as a coherent unit, integrated in terms of meaning and distributed in terms of agency over a very large number of nodes all around the planet (Scheitle, 2020). The governance of such a massive network can be problematic per se, but in the case of FFF governance, as well as in many other social movements, in fact, it equates to self-governance. In this context, rather than guiding the network, the leadership primarily reinforces it.

Along with its leadership, probably one of the key aspects promoting FFF self-governance is its strong sense of missionoriented engagement, a greater collective ethical aspiration in which all members are deeply immersed (Moor et al., 2020). The causes of climate change, the drive for sustainability, and the sense of urgency that often goes along with it are among the reasons that are behind the internal cohesion of the movement, and the motivation and involvement of thousands of youngsters. Like any movement or large group, FFF needs to reinforce its identity and remain internally compact and solid in order to cope with its dispersion. This is achieved through short, constant, and coherent messages on online platforms that enable FFF to retain its core purpose and the critical mass required to have a tangible impact on public discourse and policy stakeholders at a macrolevel. Collective agency can only function if large numbers of the internal nodes of the network are operational and are moving in the same direction. This is not easy to maintain over a long period. It will be interesting to monitor FFF going forward for any signs of decline or contraction in terms of collective organization and participation, as some researchers have already started to observe (Hunger and Hutter, 2020).

Greta Thunberg, who is a rare example of a young female being known worldwide as the leader of a massive social movement (Stratton, 2021), often explains that she is not the leader but only the spokesperson (Whang, 2020). Indeed, despite her determination and motivation, she appears to be very far from the stereotypical model of resolute, strong, and symbolically masculine leadership that is so common in Western organizations and networks. Nevertheless, or perhaps because of this discrepancy, the coordination of the school strikes and all the other initiatives around the world in the course of the last 2 years was astonishing, particularly considering that the large majority of organizers were underage students. This shows that FFF has a high capacity for self-organization and bidirectional internal coordination and decision-making, from the center to the periphery of the network and back (Meade, 2020).

\section{Political Impact}

FFF has also had a significant impact on politics and policy at an international level. Many important figures have started citing or quoting FridaysForFuture and Greta Thunberg as the source of, and inspiration for, new national and international policies. Among them, German Chancellor Angela Merkel has declared that "The seriousness with which Greta, but also many, many other young people, are telling us that this is about their lives has led us to approach the matter more resolutely" (Gaida, 2019). In her Agenda for Europe, the president of the European Commission, Ursula von der Leyen, states that she has been "inspired by the passion, conviction, and energy of the millions of our young people making their voice heard on our streets and in our hearts. They are standing up for their future and it is our generational duty to deliver for them" (European Commission. Directorate General for Communication and Leyen (2019)). On March 15, 2019, UN Secretary-General António Guterres admitted that his "generation has failed to respond properly to the dramatic challenge of climate change. This is deeply felt by young people. No wonder they are angry" (Guterres, 2019). On June 7, 2019, FridaysForFuture and Greta Thunberg became recipients of Amnesty International's Ambassador of Conscience award, and more recently, Greta Thunberg has been nominated for the Nobel Peace Prize. These and many other statements show that FFF has succeeded in conquering public political discourse and the worldwide media, and that the FFF narrative has become part of political agendas, documents, and resolutions. The extent to which such conquer is actual and not simply political/policy "green-washing" is beyond the scope of this study but would undoubtedly be worth further investigation and empirical analysis.

FFF has also provoked bitter criticism from politicians and hate speech from certain parts of the internet. Australian Prime Minister Scott Morrison told Parliament that "what we want is more learning in schools and less activism" (Wilkinson, 2018). United Kingdom former Prime Minister Theresa May criticized the strikes, saying that "Everybody wants young people to be engaged in the issues that affect them most so that we can build a 
brighter future for all of us. But it is important to emphasize that disruption increases teachers' workloads and wastes lesson time that teachers have carefully prepared for" (McGuinness, 2019). On their website, FFF responded: "Why are kids striking? School children are required to attend school. But with the worsening Climate Destruction, this goal of going to school begins to be pointless. Why study for a future which may not be there? Why spend a lot of effort to become educated, when our governments are not listening to the educated?" (FridaysForFuture 2020a)

Is it true that FFF does not provide educational and learning experiences and that it is a waste of time? Does less activism mean more learning? What kind of knowledge and learning does FFF provide, if any? The extent of FFF's impact on the political agenda and public policy is vast, and it is clear that FFF has helped to place climate change at the core of political debate, challenging those in power to address FFF requests and forcing them to respond, although the quality of the response remains to be assessed. This is very much political learning as it relates to public responsibility, responsible citizenship, democratic participation, and continuous critical thinking. Political engagement and responsibility of this nature on the part of younger generations are believed to be highly relevant for the sustainable and just transformation of society (Sannino et al., 2016; Kajamaa and Kumpulainen, 2019; Hurrelmann and Albrecht, 2020).

\section{Science-Based Learning and Activism}

In 2015, the Sustainable Development Goals (SDGs) were approved by the General Assembly of United Nations through Resolution 70/1 entitled "Transforming our World: the 2030 Agenda for Sustainable Development," shortened to Agenda 2030 (United Nations, 2015). Since then, the scientific and political attention given to climate change and sustainability has increased, including in education (e.g., Education for Sustainable Development ESD). However, while the SDGs are well-investigated top-down policies-indeed, many scholars now study and discuss the SDGs-FridaysForFuture derives from a rapid bottom-up dynamic. One of the most interesting aspects of FFF is its explicit recognition of, and declared dependence on, science, in particular but not exclusively ecological and climate science, for its themes, data, and even the terms adopted for its public campaigns (FridaysForFuture 2020a; Fisher, 2019; Stratton, 2021; Whang, 2020). One example of this is the Unite Behind Science campaign that FFF launched recently. In August 2019, Greta Thunberg sailed across the Atlantic Ocean from Europe to New York to participate in the United Nations General Assembly under the slogan "Unite Behind Science." Since the very beginning of the movement, FFF has always extolled the primacy of science over any other discourse, including the political. As far as FFF is concerned, the world should take heed of scientific warnings and indicators relating to the state of the planet and the scientific actions that need to be taken to deal with it (Whang, 2020). The trust that FFF places in science might appear naïve and uncritical, as pointed out by some scholars (Evensen, 2019; Fisher, 2019); however, it is remarkable that FFF has had the capacity to interact and collaborate so closely with scientists on a dialogic, critical, and practical basis (Kühne, 2019).
In response to the critics, ScientistsforFuture published a letter in Science in early April 2019, affirming that the climate strikers' concerns were "justified and supported by the best available science" (Hagedorn et al., 2019a). The letter was signed by more than 3,000 scientists. Some scientists have pointed out the rhetorical limitations of the FridaysForFuture movement and its initiatives and discourses (Evensen, 2019), while others have remarked on its relevance (Fisher, 2019). However, FFF has certainly generated a heated debate within the scientific community and has forced many to take a public position in some of the world's most important scientific journals.

It must be said that FFF does not create most of the scientific content it disseminates. Instead, it derives much of its technical and scientific knowledge directly from the scientific community, and then distributes it internally and externally. In this sense, FFF plays the role of bidirectional mediator and translator between science and society (Hagedorn et al., 2019b; Kühne, 2019), introducing theoretical knowledge and enactive engagement to the real world and generating a common language for it, for example, decarbonization initiatives. The scientific statements of the FridaysforFuture movement are often actively confirmed and supported by climate researchers (Hagedorn et al., 2019a; Hagedorn et al., 2019b; Fisher, 2019). Researchers agree on the extent of the greenhouse effects caused by man-made carbon emissions and conclude that increasing greenhouse gas emissions have resulted in an overall warming of the earth's climate (Hagedorn et al., 2019a). They further conclude that global warming will continue to increase if drastic measures to decrease greenhouse gas emission are not implemented worldwide. This kind of knowledge and enaction are replicated by FFF and passed on through its internal and external networks, thus demonstrating the solid foundations and reliability of the knowledge it is sharing. A strong connection with, and dependence on, scientists is therefore a key feature of FFF; this is not a trait it shares with many other social movements over the course of the last century.

\section{Paideutic Function}

Ontologically speaking, enactive systems are based on an extended and inclusive conception of the mind and on the role of knowledge and learning (Francesconi and Tarozzi, 2012; Ryan and Gallagher, 2020). In order to keep functioning, individual minds need to transform continuous incoming knowledge and to derive implicit or explicit meaning from it. In autopoietic enactive systems, knowledge is not processed as an input-output chain but is rather conceived as the capacity to adapt to the environment and shape the ecological niche (Kiverstein and Rietveld, 2018). In such systems, learning plays a twofold and crucial role: on the one side, as standard knowledge feeding of the system itself (self-feeding), where the system provides the knowledge it needs in order to continue to function; and on the other side, in the form of constant online updates on the dynamics involved with the construction of the niche and the relative adaptation (Folke et al., 2005), or, in other words, the constant monitoring of the self-environment coupling. FridaysForFuture credentials as a learning network are more 
fundamental, in that it acquires knowledge and distributes it to network participants. However, it is also much more than that. FFF has shown that it has the capacity to teach peers and adults, to direct others' learning and development, and to recommend behavior, attitudes, and terminology, which are paideutic functions. This is because FFF is normative-as a paideutic agent usually is. It distributes knowledge internally to peers and externally to society, but it also takes on an educational role in order to increase awareness and generate a sense of identity, belonging, activism, engagement, and ethical and political commitment (Reinhardt, 2019; Rucht and Sommer, 2019). All of these are pedagogical functions and goals. This is why we regard this activity as part of FFF's explicit paideutic role, and one that is directed toward peers and also adults.

In order to be able to take on a pedagogical function, it is necessary for FFF to do some preliminary work, such as knowledge partitioning (cutting knowledge into small stock of information) and knowledge sharing, and distribution through educational tools and strategies. This is evident on many FFF websites where educational resources are abundant but also through discourses and concrete behavioral examples (Wahlström et al., 2020). Initial data on this point indicate that peers are simulating the behavior and adaptive responses of the leader, Greta Thunberg, and more generally absorbing FFF messages (Deisenrieder et al., 2020). The paideutic role of FFF is exercised in constant interaction with the social environment, transferring scientific knowledge into the real world, building the capacity to learn, and providing ad hoc educational materials-which are easily accessible from their website and other platforms - to promote the incorporation of knowledge into new behaviors. In all these senses, it appears that it is possible to describe FFF as a network with paideutic properties, or even a paideutic network. As a paideutic network, FFF is capable of autonomously retrieving complex and high-quality scientific knowledge, partitioning and transforming it, and then enacting it and distributing it to society in order to try to trigger behavioral change, identity awareness, and embodied and digital activism. Behavioral change, here, refers to a wide spectrum of behavior. In particular, FFF is believed to induce change in the following areas: active knowledge seeking, engagement with climate change issues, energy and water consumption, waste separation, food consumption, consumption in general, and inclusive action to safeguard the future of the planet (Deisenrieder et al., 2020). It also means becoming acquainted with social discourses such as ecological reform, green capitalism, anti-capitalism, democratization, social justice, and much more (Marquardt, 2020). Enacting knowledge, in this case, means that FFF merges ideological reflections with everyday life, transforming it into lively topics to promote collective discussion and engagement, with a strong emphasis on what needs to be done or prevented, thus embodying the normative function so typical of educational work. In doing so, FFF contributes to the creation of the new cognitive, social, and emotional niche necessary for the establishment of the new narrative and the changes to the landscape, where new generations will grow and adopt new language, ideas, values, and behaviors (Geels and Schot, 2007; Raven et al., 2016).

\section{Ethical (Normative) Stance}

A final point in our analysis is the role of FFF as an ethical agent. As noted, FFF has the capacity to produce and enact narratives with clear goals. However, as previously stated, no action can be valued neutral, and every action derives from or is inserted post hoc into a framework of ethical values. In the case of FFF, the ethical framework and the direct connection of actions and ethics are explicitly declared: they are the ethics of responsibility and care for the human-nature connection (Reinhardt, 2019; Whang, 2020; Stratton, 2021). FFF is the embodiment of such ethical perspectives in the specific form of pragmatic wisdom (Whang, 2020; Stratton, 2021). An enactivist approach usually involves the application of practical ethics or wisdom (phronesis) (Gallagher, 2007; Gallagher, 1993). Phronesis refers not to the important role of motor skills or to the capacity to act, which is called praktognosia, but to the ability to consider value issues rationally, starting with the wisdom derived from the knowledge we (should) gain from lived bodily experiences (Di Paolo et al., 2010; Gallagher and Zahavi, 2012). In this sense, FFF's ethical approach is strongly grounded in the lived experience of the individual and the collective.

Despite the young age of its participants and leadership, FFF has demonstrated a capacity to situate practical actions, scientific knowledge, and pragmatic ethical norms within a coherent framework, and has given them a new social meaning. This kind of normative framework indicates the direction that FFF believes society, the economy, and science should follow. The alignment between all these sectors may also help to explain the vast success of FFF. FFF links everyday life with scientific knowledge and ethical statements, and places them all in a functional teleological narrative that aims to modify the governance of socio-ecological systems so that they transit toward sustainability. Despite the fact that FFF tends to emit short, clear messages-as is typical of Twitter, FFF's primary communication channel-this does not affect or diminish the power of its complex ethical messages.

As has been highlighted, FFF's general ethics are grounded in the tradition of sustainable development and care for the natural world. However, within such a general framework, it is possible to identify the variety of positions that are part of the movement. For instance, the FFF ethical framework includes deep ecology (a somewhat radical approach to ecological and climate issues) alongside anti-capitalism, green growth, and degrowth, to name but a few. Regardless of the terminological, conceptual, and philosophical variety, FFF has been able to instill a strong sense of commitment and belonging in the young population and beyond, as participation in their initiatives clearly demonstrates. It is interesting to note that a sort of reverse dynamic is underway in which young people call on adults to assume their responsibility for human development and sustainability thus far (Maier, 2020). FFF emphasizes the ethical responsibility assumed by young people and, by contrast, the lack of responsibility demonstrated by the adult world in a sort of intergenerational mismatch (Hurrelmann and Albrecht, 2020; Whang, 2020). In the competition for the dominant narrative in the limited space of public discourse, FFF has taken a pragmatic ethical approach and supported the sustainable development 
model and narrative, at least those in line with ScientistsForFuture and the Paris Agreement (FridaysForFuture, 2020a). In order to do so, and in the attempt to lobby and advocate for one ethical discourse above the many others that are available, FFF has clearly taken the normative decision to promote its own (multifaceted) perspective on the need for change in the ethics and behavior of its members and of society as a whole.

\section{CONCLUSION}

The aim of this study was to provide a theoretical conceptual analysis for FridaysForFuture as an example of collective agency that is ethically and pragmatically engaged into the heated debate about sustainable development. FridaysForFuture is a massive and recent social phenomenon that has gained widespread public visibility and attention. It is a movement made up mainly of young people, but it targets and reaches a large audience and high-level political agencies and institutions. It also has a tangible impact on national and international policies. The specific socioeconomic strata represented in FFF are not clear, but initial studies suggest that it may be based on the middle and upper classes and made up of young, female, well-educated individuals (Hunger and Hutter, 2020). FFF claims to be highly inclusive and repeatedly invites youngsters from all socioeconomic strata to participate. In addition, as we have shown, it actively builds networks with other related movements such as scientists, teachers, and parents. However, it is still relatively distant from other large-scale social movements such as Black Lives Matter. In this sense, the extended dimension of FFF as enactive network-the intention and capacity to reach out and bond with other non-environmental movements-is not yet fully understood. Clearly, overextending the boundaries of the movement's identity and the themes at its core could put at risk its ability to create and maintain a specific and easily recognizable cultural niche and sense of belonging, and this is a risk that every movement needs to assess carefully.

Deploying embodied and the enactive cognition theory and systems theory, we have described the FridaysForFuture movement as a complex social network with a nested and extended organization and function. As such, it demonstrates a high capacity for self-organization and proactive agency, the ability to enact knowledge in real life, and the ability to introduce specific ethical initiatives to promote the transformation of society. We have defined FFF as an enactive network since it has an embodied collective agency and aims to create a new social meaning and discourse by combining scientific knowledge and ethical activism. FFF brings knowledge to the social and political realms and elevates the public narrative. This movement has not only been able to create a highly nested and hyper-connected internal environment but also to extend vital connections beyond its boundaries toward other communities such as scientists, policy-makers, stakeholders, schools, students, and entrepreneurs. FFF declares itself willing to depart from earlier models of human development by stimulating informed reflection on and awareness of new models based on sustainability and the need to combat climate change.
We also suggest that FridaysForFuture has a pedagogical role. Indeed, in the context of the ever-increasing complexity of knowledge in contemporary society, FFF has demonstrated relevant skills in 1) recruiting high-level scientific knowledge without direct support from schools/teachers and in direct communication with scientists and 2) embodying strong ethical stances that specifically reference the ethics of sustainable responsibility and care for nature, and a new kind of interaction between humans and nature. FFF can therefore be interpreted as a network with transformative and normative paideutic properties that is willing to influence collective identity, awareness, and behavior, and empower collective agency by involving multilayered and nested communities in a more scientific, evidence-based, and ethical public discourse. As such, the pedagogical function of FFF goes well beyond knowledge transmission that is part of school life and reveals interesting and relevant informal, emergent, and distributed forms of learning.

Finally, we suggest that education research should devote more attention to FFF in order to address the following questions: Could formal school systems learn anything from examples such as FridaysForFuture with regard to commitment to common causes, collective agency, and engagement in order to safeguard and promote ethical values? Is there any possibility of collaboration and mutual enrichment between social movements and formal school systems? Is FridaysForFuture a replicable experience? And with what aim? We believe that FFF can stimulate formal education systems to rethink youngsters' collective agency, identity, and engagement. However, as with all emergent nonlinear processes, it could be fruitless to attempt to replicate FFF on a large scale. FFF's viral trajectory could certainly not be planned or identified in advance. Instead, it was an emergent dynamic process that, like the majority of social movements, "laid down the path by walking," starting small, and ending big. Analysis of nonlinear processes has to be often a posteriori analysis. From the day when Greta Thunberg demonstrated alone in front of the government building to today, the FFF network has grown unevenly but rapidly, branching out and spreading throughout the real and digital world. Probably, the only feasible option would be to attempt to replicate FFF's rise on a smaller scale, for example, at the school or local level, supporting students' autonomous activism and taking that as the basis for trying to impact the broader landscape where macro-dynamics happen (Geels, 2002; Geels and Schot, 2007).

The rise of FFF has had an impact on the landscape at the micro-, meso-, and macro-levels; however, schools have generally been left out. Indeed, although it has established links with informal networks of scientists, teachers, and parents, thus far FFF has shown little or no interest in dialogues with schools as formal institutions. Could this be a sign that FFF is critical of schools as formal systems? Further research is needed into how schools reacted to FFF and if and how they attempted to collaborate with the movement. It would surely be relevant from schools' point of view, and potentially innovative, to try to understand if and how it would be possible to replicate "the spirit" of FFF or respond to existing niches that can "provide the 
seeds of change" (Geels, 2002: 1,261) and eventually be scaled up. Future research should also focus on the emergence of FFF in different contexts around the world, to enhance understanding of niche and regime dynamics and FFF's ability to impact the dynamics of the landscape level (Geels, 2002).

More data and increased consideration of FFF from a theoretical perspective would advance the study of educational networks and communities (Leiviska and Pyy, 2020), especially informal ones, and clarify any potential relationship between informal student networks and formal school/educational systems. However, it will also be necessary to bear in mind the risks of regulation and control that could result from collaboration between FFF and/or other bottomup social movements, and formal educational institutions. Collaboration with schools should therefore be given careful consideration before it goes ahead. In addition, for the future, it would seem to be of great value to monitor, study, and model the virtual and embodied interaction among FridaysForFuture,

\section{REFERENCES}

Agostini, E., and Francesconi, D. (2020). Introduction to the Special Issue "Embodied Cognition and Education". Phenom Cogn. Sci. 20 (3), 417-422. doi:10.1007/s11097-020-09714-x

Albrecht, N. J. (2020). "Nature-based Mindfulness and the Development of the Ecological Self when Teaching in Higher Education," in Exploring Self toward Expanding Teaching, Teacher Education and Practitioner Research. Editors O. Ergas and J. K. Ritter First edition (Bingley: Emerald Publishing), 157-177. doi:10.1108/s1479-368720200000034010

Biswas, T., and Mattheis, N. (2021). Strikingly Educational: A Childist Perspective on Children's Civil Disobedience for Climate justice. Educ. Philos. Theor. 1-14. doi:10.1080/00131857.2021.1880390

Brünker, F., Deitelhoff, F., and Mirbabaie, M. (2019). Collective Identity Formation on Instagram - Investigating the Social Movement Fridays for Future. arXiv preprint arXiv:1912.05123.

Castellano, C., Fortunato, S., and Loreto, V. (2009). Statistical Physics of Social Dynamics. Rev. Mod. Phys. 81, 591-646. doi:10.1103/RevModPhys.81.591

Cattell, J. (2021). "Change Is Coming": Imagined Futures, Optimism and Pessimism Among Youth Climate Protesters. CJFY 13, 1-17. doi:10.29173/ cjfy 29598

Clark, A. (2013). Whatever Next? Predictive Brains, Situated Agents, and the Future of Cognitive Science. Behav. Brain Sci. 36, 181-204. doi:10.1017/ S0140525X12000477

Deisenrieder, V., Kubisch, S., Keller, L., and Stötter, J. (2020). Bridging the Action Gap by Democratizing Climate Change Education-The Case of k.i.d.Z.21 in the Context of Fridays for Future. Sustainability 12, 1748. doi:10.3390/su12051748

Di Paolo, E. A., Rohde, M., and De Jaegher, H. (2010). "Horizons for the Enactive Mind: Values, Social Interaction, and Play," In Enaction: Toward a New Paradigm for Cognitive Science/ed. J. R. Stewart, O. Gapenne, and E. A. Di Paolo (Cambridge, Mass., London: MIT Press), 32-87. doi:10.7551/ mitpress/9780262014601.003.0003

Evensen, D. (2019). The Rhetorical Limitations of the \#FridaysForFuture Movement. Nat. Clim. Chang. 9, 428-430. doi:10.1038/s41558-019-0481-1

Fisher, D. R. (2019). The Broader Importance of \#FridaysForFuture. Nat. Clim. Chang. 9, 430-431. doi:10.1038/s41558-019-0484-y

Folke, C., Hahn, T., Olsson, P., and Norberg, J. (2005). ADAPTIVE GOVERNANCE OF SOCIAL-ECOLOGICAL SYSTEMS. Annu. Rev. Environ. Resour. 30, 441-473. doi:10.1146/annurev.energy.30.050504.144511

Francesconi, D., and Tarozzi, M. (2012). Embodied Education. Studia Phaenomenologica 12, 263-288. doi:10.7761/SP.12.263

FridaysForFuture (2020a). "FridaysForFuture Website,". https://fridaysforfuture. org/. Accessed November 30, 2020.
Scientists4Future, and Entrepreneurs4Future to understand their approaches and dynamics and to consider ways in which society, science, and business can work fruitfully and ethically toward the common good.

\section{AUTHOR CONTRIBUTIONS}

DF has contributed for ideation, draft of the paper, writing the paper, revision of the paper, and final check. VS has contributed to writing the paper. EA has contributed to writing the paper, revision of the paper, and final check.

\section{FUNDING}

This research has been supported by a Marie Sklodowska-Curie Individual Fellowship (IF) under contract number 799779.

FridaysForFuture (2020b). "Strike Statistics,". https://fridaysforfuture.org/whatwe-do/strike-statistics/list-of-countries/. Accessed November 30, 2020.

Froese, T., and Di Paolo, E. A. (2011). The Enactive Approach. P\&C 19, 1-36. doi:10.1075/pc.19.1.01fro

Gaida, L. (2019). Beim Klimaschutz zeigt sich Merkel von Greta Thunberg inspiriert. Welt.

Gallagher, S., and Francesconi, D. (2012). Teaching Phenomenology to Qualitative Researchers, Cognitive Scientists, and Phenomenologists. Indo-Pacific J. Phenomenology 12, 1-10. doi:10.2989/IPJP.2012.12.3.4.1112

Gallagher, S. (2007). Moral Agency, Self-Consciousness, and Practical Wisdom. J. Conscious. Stud. 14, 199-233.

Gallagher, S. (2014). PRAGMATIC INTERVENTIONS INTO ENACTIVE AND EXTENDED CONCEPTIONS OF COGNITION. Philosophical Issues 24, 110-126. doi:10.1111/phis.12027

Gallagher, S. (1993). The Place of Phronesis in Postmodern Hermeneutics. Philos. Today 37, 298-305. doi:10.5840/philtoday199337318

Gallagher, S., and Zahavi, D. (2012). The Phenomenological Mind. 2nd ed. New York: Routledge.

Geels, F. W., and Schot, J. (2007). Typology of Sociotechnical Transition Pathways. Res. Pol. 36, 399-417. doi:10.1016/j.respol.2007.01.003

Geels, F. W. (2002). Technological Transitions as Evolutionary Reconfiguration Processes: a Multi-Level Perspective and a Case-Study. Res. Pol. 31, 1257-1274. doi:10.1016/S0048-7333(02)00062-8

Giusti, M., Svane, U., Raymond, C. M., and Beery, T. H. (2017). A Framework to Assess where and How Children Connect to Nature. Front. Psychol. 8, 2283 doi:10.3389/fpsyg.2017.02283

Guterres, A. (2019). The Climate Strikers Should Inspire Us All to Act at the Next UN Summit. The Guardian: International Edition. Available at: https://www. theguardian.com/commentisfree/2019/mar/15/climate-strikers-urgency-unsummit-world-leaders (Accessed June 20, 2021).

Hagedorn, G., Kalmus, P., Mann, M., Vicca, S., van den Berge, J., van Ypersele, J.-P., et al. (2019a). Concerns of Young Protesters Are Justified. Science 364, 2-140. doi:10.1126/science.aax3807

Hagedorn, G., Loew, T., Seneviratne, S. I., Lucht, W., Beck, M.-L., Hesse, J., et al. (2019b). The Concerns of the Young Protesters Are Justified: A Statement by Scientists for Future Concerning the Protests for More Climate protection. GAIA - Ecol. Perspect. Sci. Soc. 28, 79-87. doi:10.14512/gaia.28.2.3

Hunger, S., and Hutter, S. (2020). Online Strikes with the Usual Suspects: How Fridays for Future Has Coped with the Covid-19 Pandemic. LSE European Politics and Policy (EUROPP) blog. . Available at: http://eprints.lse.ac.uk/id/ eprint/105403 (Accessed June 20, 2021).

Hurrelmann, K., and Albrecht, E. (2020). Generation Greta: Was sie denkt, wie sie fühlt und warum das Klima nur der Anfang ist. Weinheim: Beltz.

Kahn, S., and Zeidler, D. L. (2017). A Case for the Use of Conceptual Analysis in Science Education Research. J. Res. Sci. Teach. 54, 538-551. doi:10.1002/tea.21376 
Kajamaa, A., and Kumpulainen, K. (2019). Agency in the Making: Analyzing Students' Transformative agency in a School-Based Makerspace. Mind, Cult. Activity 26, 266-281. doi:10.1080/10749039.2019.1647547

Kiverstein, J. D., and Rietveld, E. (2018). Reconceiving Representation-Hungry Cognition: an Ecological-Enactive Proposal. Adaptive Behav. 26, 147-163. doi:10.1177/1059712318772778

Kühne, R. W. (2019). Climate Change: The Science behind Greta Thunberg and Fridays for Future. Charlottesville, VA: Center for Open Science.

Leiviskä, A., and Pyy, I. (2020). The Unproductiveness of Political Conflict in Education: A Nussbaumian Alternative to Agonistic Citizenship Education. J. Philos. Edu. 00, 1-16. doi:10.1111/1467-9752.12512

European Commission. Directorate General for Communication and Leyen, U. v. de. (2019). A Union that Strives for More: My Agenda for Europe : Political Guidelines for the Next European Commission 2019 2024. Luxembourg: Publications Office of the European Union.

Lima, V. (2019). The Limits of Participatory Democracy and the Inclusion of Social Movements in Local Government. Soc. Mov. Stud. 18, 667-681. doi:10.1080/ 14742837.2019.1629277

Maier, B. M. (2020). No Planet B": An Analysis of the Collective Action Framing of the Social Movement Fridays for Future. Master thesis. Jönköping University. Available at: http://hj.diva-portal.org/smash/get/ diva2:1393821/FULLTEXT01.pdf.

Maiese, M., and Hanna, R. (2019). The Mind-Body Politic. Cham, Switzerland: Palgrave Macmillan. doi:10.1007/978-3-030-19546-5

Marquardt, J. (2020). Fridays for Future's Disruptive Potential: An Inconvenient Youth between Moderate and Radical Ideas. Front. Commun. 5, 48. doi:10.3389/fcomm.2020.00048

McGuinness, A. (2019). Theresa May Criticises Pupils Missing School to Protest over Climate Change. Sky News. Available at: https://news.sky.com/story/theresamay-criticises-pupils-missing-school-to-protest-over-climate-change-11638238 (Accessed June 20, 2021).

Meade, P. (2020). "Reaktionen auf Schüler*innenrebellion: Adultismus im Diskurs um Greta Thunberg und die "Fridays for Future"-Bewegung," in Childhood And Children's Rights between Research and Activism: Honouring The Work of Manfred Liebel. Editors R. Budde and U. Markowska-Manista (Wiesbaden: Springer VS Springer Fachmedien Wiesbaden), 85-119. doi:10.1007/978-3-658-29180-8_7

Moor, J. de., Uba, K., Wahlström, M., Wennerhag, M., and Vydt, M. de. (2020). Protest for a Future II : Composition, Mobilization and Motives of the Participants in Fridays for Future Climate Protests on 20-27 September, 2019, in 19 Cities Around the World. Charlottesville, VA: Open Society Foundations (OSF). doi:10.17605/OSF.IO/ASRUW

Newen, A., Bruin, L. de., and Gallagher, S. (2018). The Oxford Handbook of $4 E$ Cognition. First Edition. Oxford: Oxford University Press.

Papachristos, G., Sofianos, A., and Adamides, E. (2013). System Interactions in Socio-Technical Transitions: Extending the Multi-Level Perspective. Environ. Innovation Societal Transitions 7, 53-69. doi:10.1016/j.eist.2013.03.002

Petracca, E., and Gallagher, S. (2020). Economic Cognitive Institutions. J. Institutional Econ. 16, 747-765. doi:10.1017/S1744137420000144

Ransom, T. G., and Gallagher, S. (2020). Institutions and Other Things: Critical Hermeneutics, Postphenomenology and Material Engagement Theory. AI Soc., 1-8. doi:10.1007/s00146-020-00987-z

Raven, R., Kern, F., Verhees, B., and Smith, A. (2016). Niche Construction and Empowerment through Socio-Political Work. A Meta-Analysis of Six LowCarbon Technology Cases. Environ. Innovation Societal Transitions 18, 164-180. doi:10.1016/j.eist.2015.02.002

Reinhardt, S. (2019). Fridays For Future - Moral und Politik gehören zusammen. GWP - Gesellschaft. Wirtschaft. Politik 68 (2), 159-162. doi:10.3224/ gwp.v68i2.01

Roczen, N., Kaiser, F. G., Bogner, F. X., and Wilson, M. (2014). A Competence Model for Environmental Education. Environ. Behav. 46, 972-992. doi:10.1177/0013916513492416

Rodi, G. C., Loreto, V., Servedio, V. D. P., and Tria, F. (2015). Optimal Learning Paths in Information Networks. Sci. Rep. 5, 10286. doi:10.1038/srep10286

Rucht, D., and Sommer, M. (2019). Fridays for Future. Vom Phänomen Greta Thunberg, medialer Verkürzung und geschickter Mobilisierung: Zwischenbilanz eines Höhenflugs. Internationale Politik 74, 121-125UR. https://www.econstor.eu/handle/10419/222255.
Ryan, K. J., and Gallagher, S. (2020). Between Ecological Psychology and Enactivism: Is There Resonance? Front. Psychol. 11, 1147. doi:10.3389/ fpsyg.2020.01147

Sannino, A., Engeström, Y., and Lemos, M. (2016). Formative Interventions for Expansive Learning and Transformative Agency. J. Learn. Sci. 25, 599-633. doi:10.1080/10508406.2016.1204547

Scheitle, M. (2020). "Does "Fridays for Future" Really Matter? A Case Study about the Success of the Social Movement in Germany. Master thesis. Uppsala University. Available at: http://www.diva-portal.org/smash/record.jsf? pid $=$ diva2\%3A1435800\&dswid $=9509$.

Shapiro, L. (2014). The Routledge Handbook of Embodied Cognition. London, New York: Routledge.

Shove, E. (2010). Beyond the ABC: Climate Change Policy and Theories of Social Change. Environ. Plan. A. 42, 1273-1285. doi:10.1068/a42282

Smith, A., Stirling, A., and Berkhout, F. (2005). The Governance of Sustainable Socio-Technical Transitions. Res. Pol. 34, 1491-1510. doi:10.1016/ j.respol.2005.07.005

Steffen, W., Richardson, K., Rockström, J., Cornell, S. E., Fetzer, I., Bennett, E. M., et al. (2015). Planetary Boundaries: Guiding Human Development on a Changing Planet. Science 347, 1259855. doi:10.1126/science.1259855

Stratton, C. (2021). Greta Thunberg: Climate Activist. Lake Elmo MN: Focus Readers. doi:10.1158/1538-7445.sabcs20-sp147

Thompson, E. (2007). n. 1. in Mind in Life: Biology, Phenomenology, and the Sciences of Mind/Evan Thompso. paperback ed. Cambridge, Mass., London: Harvard Univ. PressThe Belknap Press of Harvard University Press.

United Nations (2015). Transforming Our World. The 2030 Agenda for Sustainable Development. Paris: United Nations.

Varela, F. J., Thompson, E., and Rosch, E. (2016). The Embodied Mind: Cognitive Science and Human Experience. revised edition. Cambridge Massachusetts, London England: MIT Press.

Wahlström, M., Kocyba, P., Vydt, M. de., Moor, J. de., Adman, P., Balsiger, P., et al. (2019). "Protest for a Future: Composition, Mobilization and Motives of the Participants," in Fridays for Future: Surveys of Climate Protests on 15 March, 2019 in 13 European Cities. doi:10.17605/OSF.IO/XCNZH

Wahlström, M., Moor, J. de., Uba, K., Wennerhag, M., Vydt, M. de., Almeida, P., et al. (2020). Surveys of Participants in Fridays for Future Climate Protests on 2028 September, 2019, in 19 Cities Around the World: Open Science Framework. Charlottesville, VA: Open Society Foundations (OSF). doi:10.17605/OSF.IO/ ASRUW

Walker, B., Carpenter, S. R., Folke, C., Gunderson, L., Peterson, G. D., Scheffer, M., et al. (2020). Navigating the Chaos of an Unfolding Global Cycle. EઐS 25. doi:10.5751/ES-12072-250423

Whang, O. (2020). Greta Thunberg Reflects on Living through Multiple Crises in a 'post-truth Society. National Geographic. doi:10.21437/interspeech.20202153 Available at: https:/www.nationalgeographic.com/environment/article/ greta-thunberg-reflects-on-living-through-multiple-crises-post-truth-society (Accessed June 20, 2021)

Wilkinson, B. (2018). Australian School Children Defy Prime Minister with Climate Strike. $C N N$. Available at: https://edition.cnn.com/2018/11/30/australia/australiaschool-climate-strike-scli-intl/index.html (Accessed June 20, 2021).

Zabern, L. von., and Tulloch, C. D. (2020). Rebel with a Cause: The Framing of Climate Change and Intergenerational justice in the German Press Treatment of the Fridays for Future Protests. Media, Culture \& Society 43 (1), 23-47. doi:10.1177/0163443720960923 CrossRef Full Text

Conflict of Interest: The authors declare that the research was conducted in the absence of any commercial or financial relationships that could be construed as a potential conflict of interest.

Copyright (๑) 2021 Francesconi, Symeonidis and Agostini. This is an open-access article distributed under the terms of the Creative Commons Attribution License (CC $B Y$ ). The use, distribution or reproduction in other forums is permitted, provided the original author(s) and the copyright owner(s) are credited and that the original publication in this journal is cited, in accordance with accepted academic practice. No use, distribution or reproduction is permitted which does not comply with these terms. 